\title{
Challenging times for mental health services
}

\author{
Matt Muijen MD PhD
}

Regional Adviser for Mental Health, World Health OrganizationRegional Office for Europe, email mfm@euro.who.int

\begin{abstract}
W e are living in significant and challenging times for mental health services across the world. On the one hand, many countries are in the middle of comprehensive reforms of their mental health systems, and these require funding (WHO Europe, 2008). On the other, they are affected by the global financial crisis as regional and national economic recessions threaten to herald a social crisis in many countries. Governments have had to come up with multi-billion-dollar rescue packages. At an individual level, debt status is already high in many countries, owing to falling house prices and high consumption levels, combined with rising commodity prices during the past few years, before the onset of the recession. At a public level, countries will be forced to make stringent cuts in public sector expenditure.
\end{abstract}

\section{Consequences of the crisis}

The crisis has several consequences for the mental health of the population. Loss of employment and risk of unemployment are associated with increases in stress, anxiety, depression and psychotic disorders. An economic crisis and loss of employment are also associated with an increase in suicide (Stuckler et al, 2009). Debt is particularly important as a factor causing depression. In a national survey of private households in England, Scotland and Wales, a clear link between debt and poor mental health was found (Jenkins et al, 2008).

In low-income countries, loss of jobs can cause absolute poverty (in contrast to the relative poverty it causes in highincome countries), with potentially disastrous consequences for health, including mental health (Commission on Social Determinants of Health, 2008). Access to healthcare can be restricted, and the risk of debt increased, especially in the many lower-income countries where assessment and treatment, including the purchasing of medication, demand some out-of-pocket payment, whether formally or not.

For people with severe mental disorders, the large majority of whom are already unemployed and at risk of living in poverty (Aro et al, 1995; Harvey et al, 2009), the consequences will be different. There is less evidence that the prevalence of these disorders is directly affected by an economic crisis, but opportunities for integration may diminish yet further, and stigma and discrimination may grow. Unemployment increases competition for placements in protected workplaces or social firms, which will be tempted to select the more able, and this heightens further the risk of exclusion for the most vulnerable people. The emphasis on finding paid employment for those with mental health problems, so important for their self-respect and social inclusion, may be undermined in an increasingly restricted job market. Companies struggling to make a profit may become more sensitive to any perceived risks of lower productivity on the part of present or future employees, even if that perception is based on irrational grounds in many instances, such as a history of depression.

\section{Mental health services}

These social and economic developments are taking place at a point in time when mental health services are in transformation. The past 5 years have seen a high level of mental health policy and service development (WHO Europe, 2008). Almost all of the 53 European member states of the World Health Organization (WHO) now have mental health policies that aim to deliver community-based mental health services along the priorities of the Helsinki Declaration (WHO Europe, 2005). There is consensus that crisis and home care services need to be established alongside small-scale hospital units, empowering users and carers. Many countries are now at the point where investments are essential if these policies are to be put into practice, rather than remaining aspirational. Only a few countries presently have supported the development of community services targeting vulnerable groups, and these are typically the countries where investment in mental healthcare was high even before any reform.

A particular challenge at an international level is the tremendous variation in existing provisions, despite the convergence of policies. Whether one considers numbers of hospital beds, admissions, psychiatrists or nurses, all vary many-fold, even between neighbouring countries. Particularly in poorer countries, staff essential for the effective operation of community services, such as social workers and psychologists, hardly exist. Unsurprisingly, the strongest predictor of provision of services is the level of funding, which is in turn correlated to the wealth of the country (Shah, 2009), but efficient investment is equally important. Many poor countries spend a very large proportion of their mental health budget on a relatively small number of hospital beds, benefiting few (WHO Europe, 2008).

Although further investment is essential at this stage of development, many governments are facing the need to reduce expenditure. Public sector spending will be scrutinised and cuts made in areas not considered a political priority, and the severity of the cuts will depend on the overall economic health of the country as much as the perceived importance of the service.

Unfortunately, mental health services are interdependent, and the closure of one component will affect all other parts. For example, cuts in social services can shift some of the burden of care to health services, particularly for 
young and elderly people. The most dependent are particularly vulnerable, since the evidence of efficiency of intensive support services is rarely available or accepted, especially in lower-income countries. Specifically, community mental health services are often cut, since their disappearance does not involve the closure of hospitals on which local economies depend. The consequence will be that services which aim to reduce the need for admission will have reduced capacity, putting growing demand on more expensive institutional services. This in turn means that primary care services will be swamped by people with severe mental disorders, and will therefore not be able to deal with common problems that are particularly important from a population and economic perspective, such as depression and anxiety. The effects on health as a whole and on mental health specifically are both inequitable and inefficient.

\section{Effective interventions for mental health during a financial crisis}

How a nation protects its health has a significant effect on its economic competitiveness and prosperity. An example of a sensible response is the high profile given to the consequences for the economy of the spread of the H1N1 flu virus, and the willingness of countries to invest in prevention and early intervention. If the comparative burden of disease and the social and economic impact of mental disorders are considered, a strong case is made for investment in mental health capital.

Effective approaches are needed to respond to the damaging consequences of an economic recession and its negative impact on mental health at individual and societal levels. Interventions must therefore address social, public health and individual needs.

At a societal level, considering the direct link between employment, income, status and mental health, supply-side economic measures will benefit mental health, especially infrastructure investments that create jobs, and the provision of universal and free health coverage (Sen, 2009).

At a provider and individual level, a recession is a time to protect essential community services for the most vulnerable and to advocate the development of additional evidencebased interventions, such as the provision of meaningful activities for unemployed people with mental health problems, the screening of people at risk, the training of family doctors in the detection and treatment of depression, and better access to therapies.
The economic crisis requires us to focus on mental health priorities and effective interventions if we are to make a convincing case for sustained, let alone additional investment. The temptation for politicians, who are facing tough decisions about cuts in healthcare, is to select 'soft' areas that do not result in public outcries, and to ignore existing inequalities such as the conspicuous high mortality rates of people with mental disorders (Hiroeh et al, 2008). Our challenge is to change mental health into a 'deserving' priority area by demonstrating existing inequities, the further damage of cuts to individuals and society, and the benefits of new investment. There is place for some optimism, since an increasing number of countries are committed to mental health reform, which now has to be accelerated and sustained. This will prove to be a crucial test for mental health advocates, but the increasing effectiveness of international networks in raising awareness makes successful reform more likely.

\section{Acknowledgement}

I would like to acknowledge the support of Dr Anja Baumann in the preparation of an earlier version.

\section{References}

Aro, S., Aro, H. \& Keskimäki, I. (1995) Socio-economic mobility among patients with schizophrenia or major affective disorder. A 17-year retrospective follow-up. British Journal of Psychiatry, 166, 759-767.

Commission on Social Determinants of Health (2008) Closing the Gap in a Generation. WHO.

Harvey, S. B., Henderson, M., Lelliott, P., et al (2009) Mental health and employment: much work still to be done. British Journal of Psychiatry 194, 201-203.

Hiroeh, U., Kapur, N., Webb, R., et al (2008) Deaths from natural causes in people with mental illness: a cohort study. Journal of Psychosomatic Research, 64, 275-283.

Jenkins, R., Bhugra, D., Bebbington, P., et al (2008) Debt, income and mental disorder in the general population. Psychological Medicine 38, 1485-1493.

Sen, A. (2009) Capitalism beyond the crisis. New York Review of Books, $5,27-30$.

Shah, A. (2009) The relationship between socio-economic status and mental health funding, service provision and national policy: a crossnational study. International Psychiatry, 6, 44-46.

Stuckler, D., Basu, S., Suhrcke, M., et al (2009) The public health effect of economic crises and alternative policy responses in Europe: an empirical analysis. Lancet, online DOI: 10.1016/50140-6736(09)61124-7.

WHO Europe (2005) Mental Health Declaration for Europe. WHO Europe. Available at http://www.euro.who.int (accessed October 2009).

WHO Europe (2008) Policies and Practices for Mental Health in Europe. WHO Europe. Available at http://www.euro.who.int (accessed October 2009).

It may seem a strange principle to enunciate as the very first requirement in a Hospital that it should do the sick no harm.

Florence Nightingale, English nurse, Notes on Hospitals (1863 edn), preface 